\title{
Physical properties of sessile oak (quercus petraea l) used by the wood industry in Kosovo
}

\author{
Rrahim SEJDIU $^{1 *}$, Florit HOXHA ${ }^{\mathbf{1}}$, Bujar JASHARI ${ }^{\mathbf{1}}$, Lulzim IDRIZI ${ }^{\mathbf{1}}$, \\ ${ }^{1}$ Faculty of Architecture, Design and Wood Technology, University of Applied Sciences - \\ "Universiteti" Ferizaj, Kosovo, \\ E-mail: rrahim.sejdiu@ ushaf.net,
}

\begin{abstract}
The paper shows some physical properties of sessile oak obtained in Kosovo regions.

In the study are shown: wood shrinkage, specific gravity, shrinkage coefficient for $1 \%$ change of moisture content, ratio of shrinkage in tangential and radial direction etc.

The amount of volumetric shrinkage of sessile oak is $15.95 \%$, heartwood part has an average shrinkage $15.41 \%$ in

The shrinkage of sapwood part is $17.56 \%$. Specific gravity at: wet condition: $\left(1.013 \mathrm{gr} / \mathrm{cm}^{3}\right)$; $12 \%\left(0.853 \mathrm{gr} / \mathrm{cm}^{3}\right)$ and $0 \%\left(0.826 \mathrm{gr} / \mathrm{cm}^{3}\right)$ of moisture content.

Specific gravity of heartwood at: wet condition $(1.05 \mathrm{gr} / \mathrm{cm} 3) ; 12 \%\left(0.88 \mathrm{gr} / \mathrm{cm}^{3}\right) ; 0 \%$ $\left(0.85 \mathrm{gr} / \mathrm{cm}^{3}\right)$. The specific gravity of sapwood at: wet condition $\left(0.91 \mathrm{gr} / \mathrm{cm}^{3}\right) ; 12 \%\left(0.77 \mathrm{gr} / \mathrm{cm}^{3}\right)$; $0 \%\left(0.748 \mathrm{gr} / \mathrm{cm}^{3}\right)$.

The ratio of average shrinkage between tangential and radial cutting direction is $1.71 \%$. This ratio was significantly higher in sapwood than heartwood.

Coefficient of shrinkage (changing $1 \%$ of moisture content) in the radial direction is 0.00196 , and 0.00323 in tangential direction.

Keywords: Physical properties, sessile oak, specific gravity, shrinkage.
\end{abstract}

\section{INTRODUCTION}

The most important varietes of wood that grows up in Kosovo are Beech wood (Fagus) with a volume

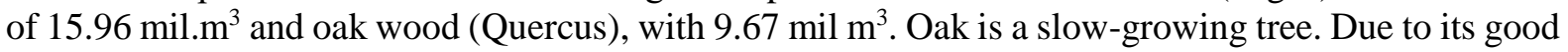
characteristics, ( having some chemical components which are used to flavor the wine barrels, beautiful texture on radial and tangential cutting direction and other good mechanical properties) the sessile oak tree is fairly used in the wood processing industry [1]. This type of wood is mostly used to make doors, windows, flooring, barrels and many other products.

Based on studied datas which shows that the dry oak tree is being used in furniture enterprises with an average of $2800 \mathrm{~m}^{3}$, making it among the most important woods in Kosovo's processing industry [2], the same study also shows that: out of total $2210 \mathrm{~m}^{3}$ dry timber get provided from import, and about $600 \mathrm{~m}^{3}$ provided by country.

Sessile oak (Quercus Petraea L) is a sort of wood with slower growing tree, it mainly dries very slowly with a tendency to split and check, particularly in the early stages of drying. It cracs very easely during kiln drying.

Working by hand or machine on the timber can be medium to hard. It will depend on weather the timber is wet or dry [3]. Wet timber is easier to work on, but tools will stain the timber more, the dust will be less of a problem, which can be an irritant when it gets dry. Working on dry timber can be very hard, tools will have to be sharpened more and regularly. 
The heartwood of oak is very hard and it has some chemical compunds. Because of very high tannin content heartwood of oak does not need to be treated against decay or insect attack if it is used in interior areas.

The sap wood of oak is very soft and very susceptible to decay and insects attack and also has no load bearing capabilities, so it should be avoided to be used in construction work [4].

Chemical properties, iron staining may occur in damp conditions, or when working on fresh timber with tools. Metal fixings can get corrosion. Also the tannin can stain hands blue/grey when working on fresh timber, also can be very hard to remove.

The scientific paper shows some physical properties of this type of wood.

\section{MATERIALS AND METHODS}

For the study is taken sessile oak wood (Quercus Petraea L) which grows up in the territory of Kosovo, in altitude from $500-800 \mathrm{~m}$.

In these regions the climate is continental, resulting with hot summers and cold winters with Alpine and Mediterranean influences. The temperatures move from $-20^{\circ} \mathrm{C}$ in winter to $+30^{\circ} \mathrm{C}$ during the summer.

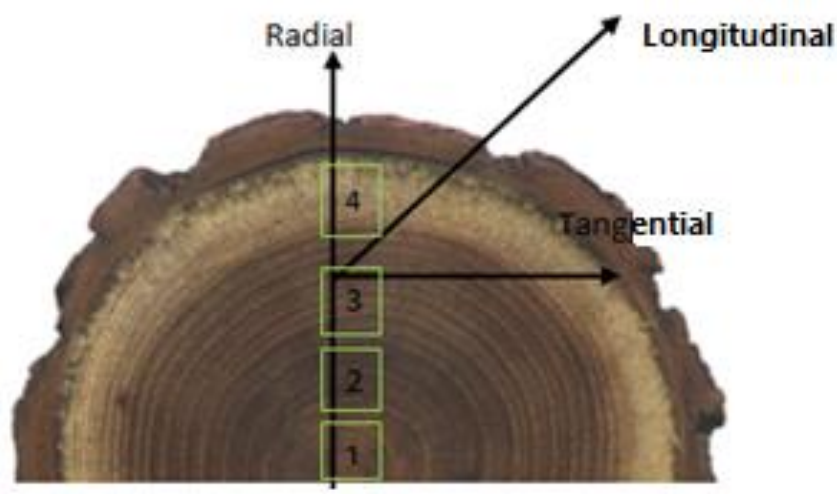

Figure 1. Position of samples in the tree

Table 1. The average temperature of the regions where the samples are taken [5].

\begin{tabular}{lccccccccccccc}
\hline \multicolumn{110}{c}{ Annual average for years 1960-2008 } \\
\hline Month & I & II & II & IV & V & VI & VII & VIII & IX & X & XI & XII & Ave \\
Aver temp. ${ }^{\circ}$ C & -0.8 & 1.3 & 5.5 & 10.3 & 15.1 & 18.9 & 20.9 & 20.6 & 15.9 & 11.2 & 5.7 & 1.4 & 10.5 \\
Relat. humidity \% & 82.4 & 77.7 & 71.9 & 67.8 & 69.5 & 68.5 & 64.2 & 60.7 & 69.9 & 74.2 & 81.0 & 84.5 & 72.7 \\
\hline
\end{tabular}

Cutting samples are taken with dimensions $(20 \times 20 \times 20 \mathrm{~mm})[6]$, and dried in elctronic oven in temperature $102 \pm 3^{\circ} \mathrm{C}$, for four hours. Time by time these samples are weighted and measured in dimensions. After three consecutive measures samples has given the same weight (changed $0.1 \%$ ), then those are considered oven dried.

For sample calculations are used formulas [7]:

Moisture content:

$$
\text { Wood Moisture (\%) }=\frac{G_{l}-G_{0}}{G_{0}} \times 100[\%]
$$

Were:

G-Weight of moisture wood ,

$\mathrm{G}_{0}$-Weight of oven dried wood.

Shrinkage of wood: 


$$
\text { Shrinkage }(\%)=\frac{\text { Initial dimensions }- \text { Final dimensions }}{\text { Initial dimensions }} \times 100 \%
$$

Specific gravity:

$$
\delta=\operatorname{Mass} / \operatorname{Volum}\left(\mathrm{gr} /\left(\mathrm{cm}^{\wedge} 3\right)\right)
$$

Number of samples for each group was 35, in total 140 samples (figure 2). Samples of groups were taken from the center of sessile oak toward the periphery, as shown in figure 1.

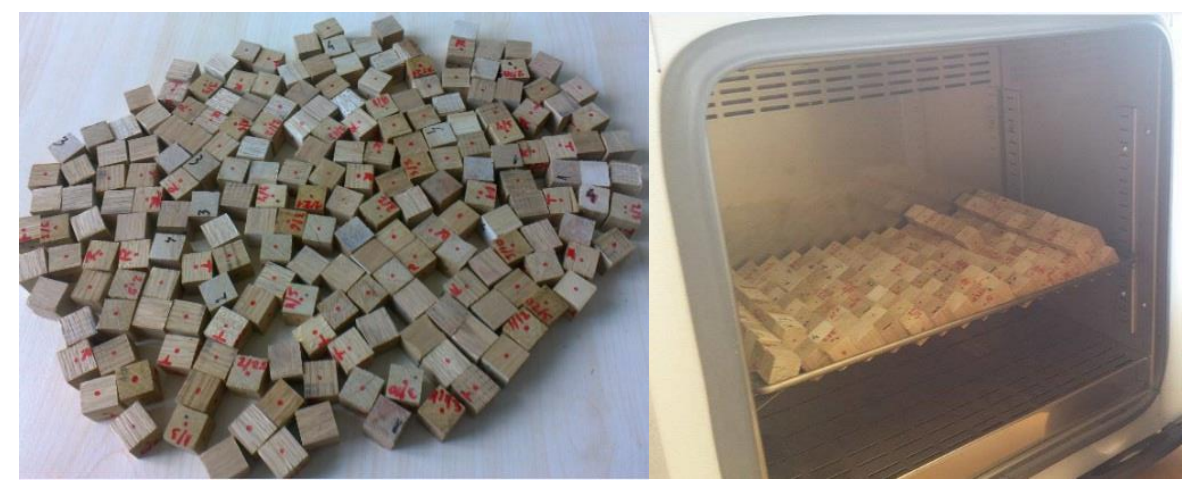

Figure 2. Preparing samples for the study

\section{RESULTS}

Table 2. Average shrinkage of sessile oak wood in three cutting directions and the amount of volumetric shrinkage, in two different moisture content (0 and 12\%).

\begin{tabular}{lcccc}
\hline \multicolumn{1}{c}{ Average Shrinkage } & Longitudinal & Radial & Tangential & Volumetric \\
\hline Shrinkage at 0\% & $0.38 \%$ & $5.88 \%$ & $9.69 \%$ & $15.95 \%$ \\
Shrinkage at 12\% & $0.22 \%$ & $2.96 \%$ & $5.20 \%$ & $8.10 \%$ \\
Standard deviation at 0\% & $\pm 0.27 \%$ & $\pm 0.76 \%$ & $\pm 1.17 \%$ & $\pm 1.56 \%$ \\
Standard deviation at 12\% & $\pm 0.14 \%$ & $\pm 0.72 \%$ & $\pm 0.96 \%$ & $\pm 1.39 \%$ \\
\hline
\end{tabular}




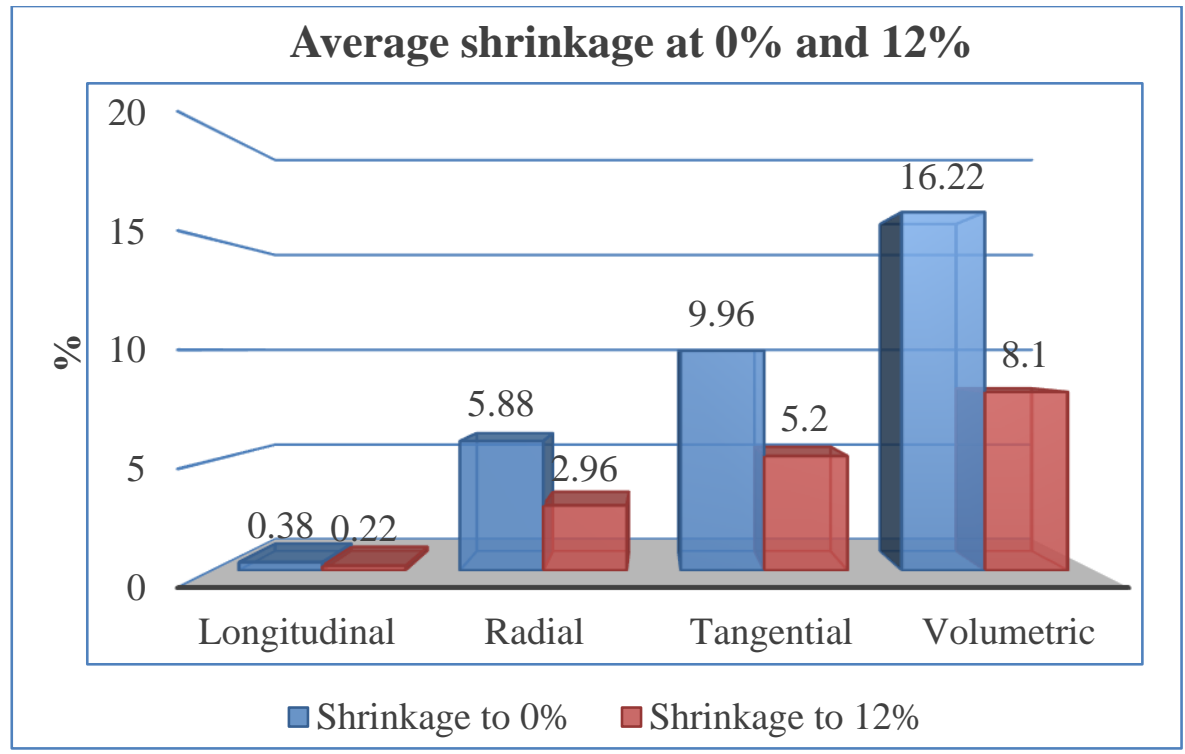

Figure 3. Average shrinkage in two different moisture content (0 and 12\%)

Table 3. Average shrinkage of heartwood in three cutting direction and volumetric shrinkage at $(0$ and $12 \%)$ moisture content.

\begin{tabular}{lcccc}
\hline \multicolumn{5}{c}{ Heartwood } \\
\hline Average Shrinkage & Longitudinal & Radial & Tangential & Volumetric \\
Shrinkage at 0\% & $0.34 \%$ & $6.22 \%$ & $8.86 \%$ & $15.41 \%$ \\
Shrinkage at 12\% & $0.22 \%$ & $2.84 \%$ & $4.50 \%$ & $7.55 \%$ \\
Standard deviation at 0\% & $\pm 0.28 \%$ & $\pm 0.78 \%$ & $\pm 0.98 \%$ & $\pm 1.47 \%$ \\
Standard deviation at 12\% & $\pm 0.12 \%$ & $\pm 0.69 \%$ & $\pm 0,84 \%$ & $\pm 1.34 \%$ \\
\hline
\end{tabular}

Table 4. Average shrinkage of sapwood in three cutting direction and the volumetric shrinkage at (0 and $12 \%$ ) moisture content.

\begin{tabular}{lcccc}
\hline \multicolumn{5}{c}{ Sapwood } \\
Average Shrinkage & Longitudinal & Radial & Tangential & Volumetric \\
Shrinkage at 0\% & $0.51 \%$ & $4.86 \%$ & $12.18 \%$ & $17.55 \%$ \\
Shrinkage at 12\% & $0.21 \%$ & $2.23 \%$ & $7.28 \%$ & $9.72 \%$ \\
Standard deviation atb0\% & $\pm 0.24 \%$ & $\pm 0.69 \%$ & $\pm 1.73 \%$ & $\pm 1.80 \%$ \\
Standard deviation at 12\% & $\pm 0,27 \%$ & $\pm 0.87 \%$ & $\pm 1.28 \%$ & \pm 1.56 \\
\hline
\end{tabular}




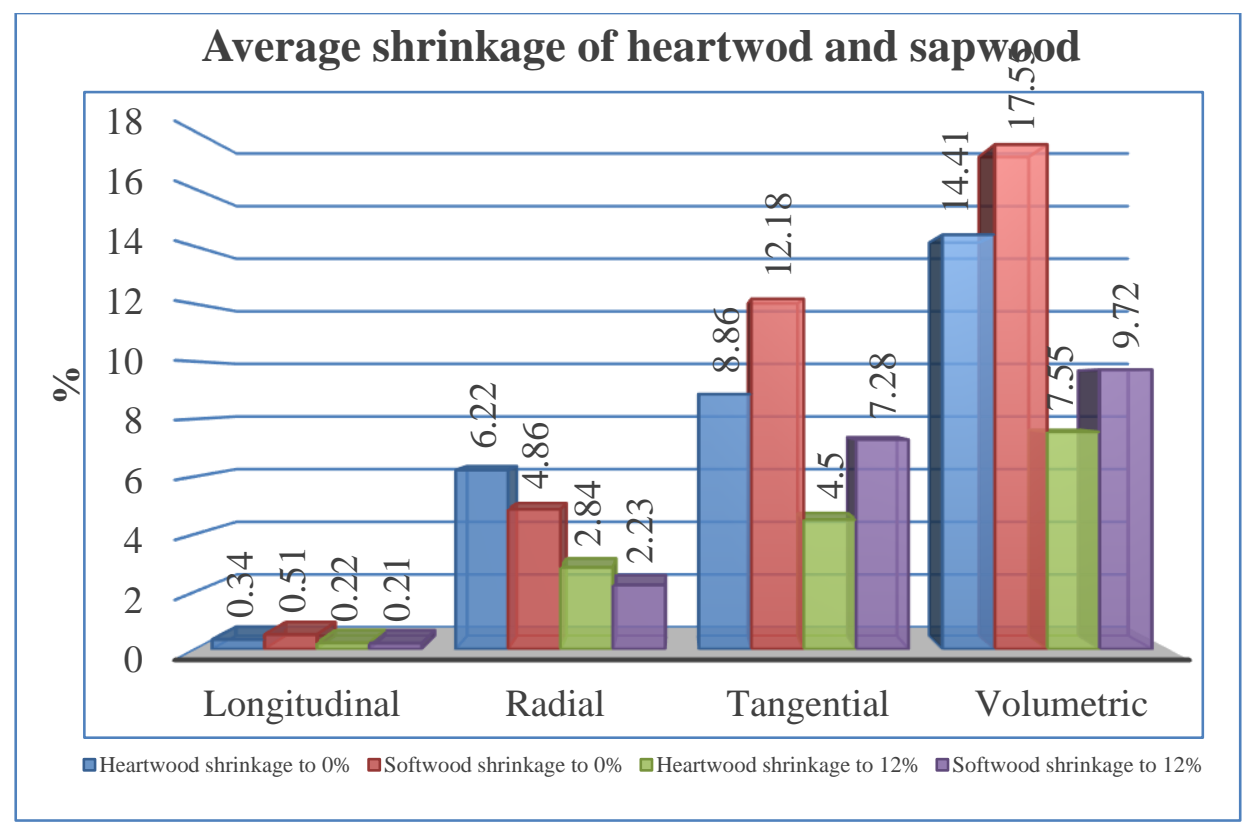

Figure 4. Average shrinkage of heartwood and sapwood in two different moisture content ( 0 and $12 \%$ )

Table 5. Average shrinkage of sessile oak depending of the samples in the tree (see figure 1).

\begin{tabular}{rcccc}
\hline Shrinkage & Longitudinal & Radial & Tangential & Volumetric \\
\hline Sample I & $0.33 \%$ & $6.56 \%$ & $9.31 \%$ & $16.20 \%$ \\
Sample II & $0.40 \%$ & $6.49 \%$ & $8.10 \%$ & $14.98 \%$ \\
Sample III & $0.29 \%$ & $5.60 \%$ & $9.17 \%$ & $15.06 \%$ \\
Sample IV & $0.51 \%$ & $4.86 \%$ & $12.18 \%$ & $17.56 \%$ \\
\hline
\end{tabular}

Figure 5. Average shrinkage of samples in the tree 


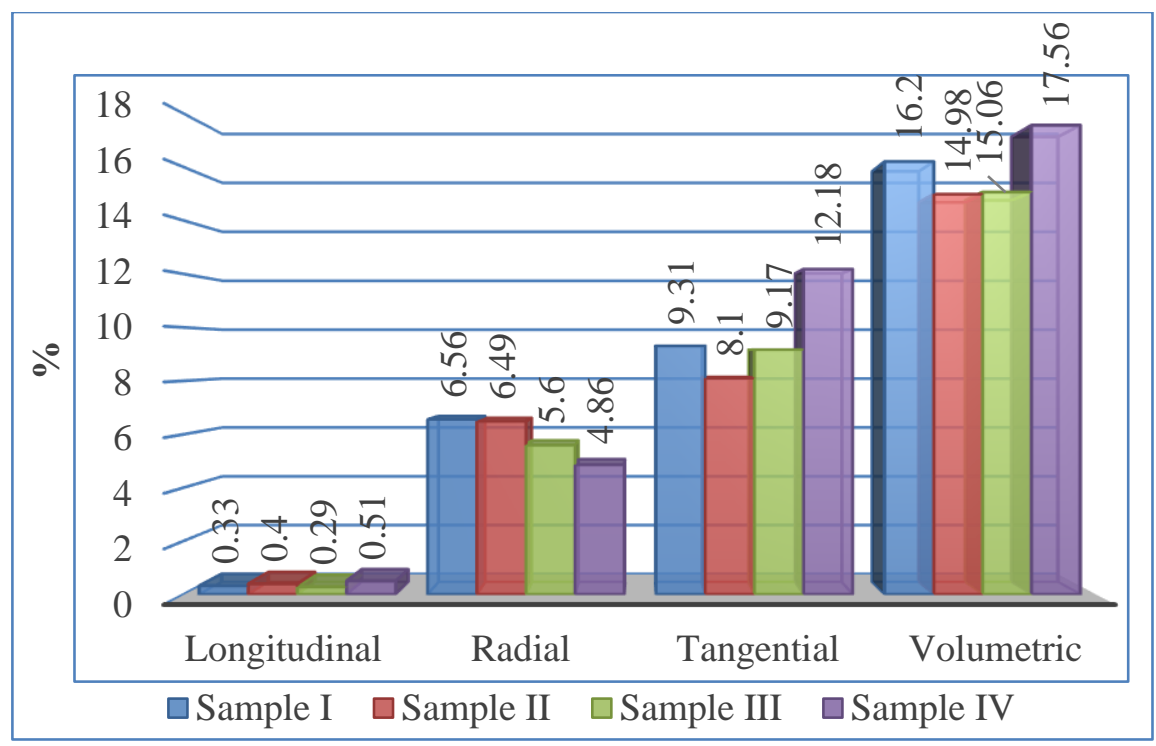

Table 6. Specific gravity of sessile.

\begin{tabular}{lccc}
\hline \multicolumn{4}{c}{ Specific gravity gr/cm } \\
\hline Moisture & wet & $12 \%$ & $0 \%$ \\
Sample I & 1.09 & 0.90 & 0.87 \\
Sample II & 1.03 & 0.86 & 0.84 \\
Sample III & 1.03 & 0.85 & 0.84 \\
Sample IV & 0.91 & 0.77 & 0.75 \\
Average & 1.013 & 0.853 & 0.826 \\
Standard Deviation & $\pm 1.81 \%$ & $\pm 1.41 \%$ & $\pm 1.42 \%$ \\
\hline
\end{tabular}

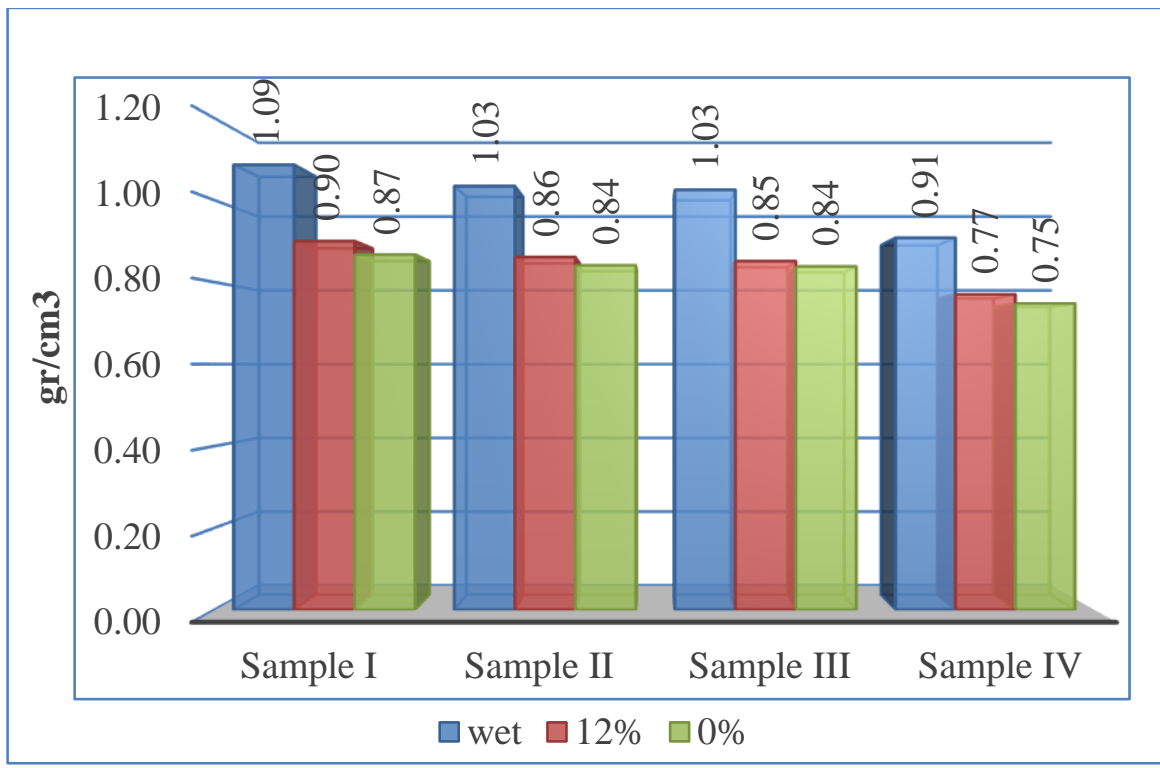

Figure 6. Specific gravity of the samples in the tree $\mathrm{gr} / \mathrm{cm}^{3}$ 
Table 7. Shrinkage ratio in tangential/radial direction:

\begin{tabular}{ll}
\hline \multicolumn{2}{c}{ Ratio T/R } \\
\hline Sample I & 1.420 \\
Sample II & 1.257 \\
Sample III & 1.637 \\
Sample IV & 2.529 \\
Average & 1.711 \\
\hline
\end{tabular}

Table 8. Coefficient of shrinkage at $1 \%$ of changing moisture content.

\begin{tabular}{lcc}
\hline \multicolumn{3}{c}{ Shrinkage coefficient at $\mathbf{1 \%}$ of moisture change } \\
\hline & Radial & Tangencial \\
Sample I & 0.002186 & 0.003104 \\
Sample II & 0.002162 & 0.002700 \\
Sample III & 0.001868 & 0.003057 \\
Sample IV & 0.001621 & 0.004061 \\
Average & 0.00196 & 0.00323 \\
Standard Deviation & \pm 0.00023 & \pm 0.00050 \\
\hline
\end{tabular}

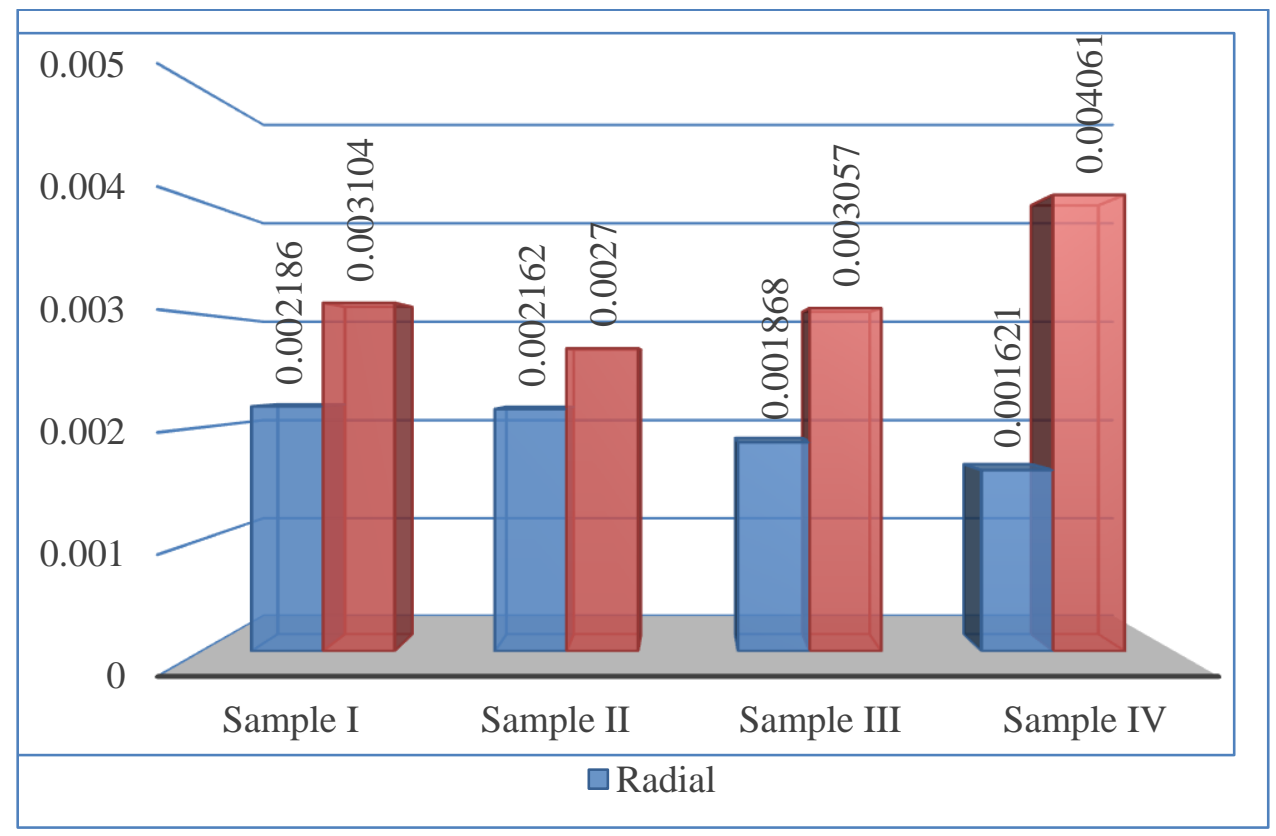

Figure 7. Shrinkage coefficient at $1 \%$ of moisture change 


\section{CONCLUSION}

The amount of volumetric shrinkage of sessile oak from 30-0\% moisture content is $15.95 \%$, meanwhile till $12 \%$ the shrinkage is $8.1 \%$.

Heartwood part, has an average shrinkage $15.41 \%$ in $0 \%$ and $7.55 \%$ in $12 \%$ of moisture content. The shrinkage of sapwood part in $0 \%$ of moisture content is $17.56 \%$, meanwhile in $12 \%$ the shrinkage was $9.73 \%$.

Based on the position of the samples in the tree shows that; the group of samples 4 and 1 are shrinking mostly, with $17.56 \%$ and $16.2 \%$, while smaller shrinkages are found in samples 2 and 3, respectively $15.06 \%$ and $14.98 \%$.

Specific gravity at: wet condition: $\left(1.013 \mathrm{gr} / \mathrm{cm}^{3}\right) ; 12 \%\left(0.853 \mathrm{gr} / \mathrm{cm}^{3}\right)$ and $0 \%\left(0.826 \mathrm{gr} / \mathrm{cm}^{3}\right)$ of moisture content.

Specific gravity of heartwood at: wet condition $\left(1.05 \mathrm{gr} / \mathrm{cm}^{3}\right) ; 12 \%\left(0.88 \mathrm{gr} / \mathrm{cm}^{3}\right) ; 0 \%\left(0.85 \mathrm{gr} / \mathrm{cm}^{3}\right)$. The specific gravity of sapwood at: wet condition $\left(0.91 \mathrm{gr} / \mathrm{cm}^{3}\right) ; 12 \%\left(0.77 \mathrm{gr} / \mathrm{cm}^{3}\right) ; 0 \%\left(0.748 \mathrm{gr} / \mathrm{cm}^{3}\right)$. The ratio of average shrinkage between tangential and radial cutting direction is $1.71 \%$.

This ratio was significantly higher in sapwood than heartwood. Coefficient of shrinkage (changing $1 \%$ of moisture content) in the radial direction is 0.00196 , and 0.00323 in tangential direction.

References

[1] Bajraktari et. al., «Forest Resources and Sawmill Structure of Kosovo: State of the Art and Perspectives,„» DRVNA INDUSTRIJA, vëll. i 65, nr. 4, pp. 323-327, 2014.

[2] R. Sejdiu, STUDY ON ARTIFICIAL WOOD DRYING CAPACITIES IN THE TERRITORY OF THE REPUBLIC OF KOSOVO, Tirana: University of Tirana, 2016.

[3] W. T. Simpson, DRY KILN Operator's Manual US. Departament of Agriculture Forest Service., Forest Service, Forest Products Laboratory, 1991.

[4] http://www.timbergardenbuild.co.uk/faq-s/timber-used-in-construction/about-oak/.

[5] Sejdiu et. al., Changes of Equilibrium Moisture during the Natyral Drying of Wood in the Territory of Kosovo (for years 1960-2008), International Journal of Current Engineering and Technology., pp. 653-654, 2015.

[6] J. Josue, Some wood properties of Xylia xylocarpa planted in Sabah, Sepilok Bulletin, pp. 1-15, (2004.

[7] Entela Lato, Doklea Quku,, Study of Wood, Macroscopic structure and properties of wood,, Tirana, 2008, p. 84.

[8] Sejdiu et. al., The Relationships between Density and Shrinkage of Sessile Oak (Quercus Petraea L) Used For Alcohol Barrels: (A case study of Wood that grows in the Republic of Kosovo),, Journal of Engineering and Architecture, vëll. i 3, nr. 2, pp. 57-72, 2015. 